\title{
REVIEW OF EXPERIMENTAL RESEARCH IN SYPHILIS AND ITS POSSIBLE APPLICATION TO MAN*
}

\author{
By L. W. HARRISON
}

WHEN I undertook to review the experimental work in syphilis which has been carried on for a number of years the task seemed likely to prove a comparatively light one, because I had in mind the presentation of a few general conclusions which seemed to me of particular interest from the point of view of their application to the problem of human syphilis. At closer and closer quarters it became increasingly formidable as I became more and more conscious of the impossibility of condensing into the short space of time at my disposal anything approaching an adequate summary of the subject. I have been compelled, therefore, to limit my range to sections which seemed to be of more practical interest, and even so cannot do justice to the work of the numerous experimenters. If my review should be deemed worthy of publication in our JoURNAL, I would ask readers to remember that it is no guide to priority of discovery, nor does it pretend to include anything but a fraction of the experimental work in this field of medicine. It may, however, serve as an introduction for those who have not studied a subject which has been for me one of absorbing interest, mainly, I think, because of the guidance it offers in the management of syphilis in man.

I would first review the experimental work which seems to enlighten the question of the behaviour of the tissues in the face of an invasion by $S p$. pallida. It is well known that shortly after the appearance of the primary sore in man reinoculation usually fails to provoke a second chancre. It is also known that for many years, perhaps for life, after subsidence of the early symptoms, the disease may remain quite dormant so far

* Based on an address delivered before the Medical Society for the Study of Venereal Diseases, May 3 Ist, 1929. 


\section{BRITISH JOURNAL OF VENERAL DISEASES}

as anything save serological tests can tell us. Is this because the tissues develop substances or properties which are actively antagonistic to $S p$. pallida, or because they require a tolerance of the parasite ? The common belief accords with Neisser's view that resistance to reinfection and latency are due to non-reaction of the tissues, or " anergie" as Neisser called it, a condition said to depend entirely on the continued presence of the virus. Conversely, the appearance of a second chancre is commonly held to be proof that the first infection was eradicated.

This review will present evidence that, although " anergie" may explain the non-development of a chancre or reinoculation in certain cases, an active resistance to $S p$. pallida is a factor in preventing reinfection. Also, that " anergie" is not dependent on the presence of $S p$. pallida in the tissues, but is either natural or results from interaction between the tissues and the parasites, and persists after the spirochætes have been destroyed. If this case is proved, it follows that failure to infect by reinoculation does not imply that the first infection was not eradicated.

Natural " anergie," either complete or partial and not dependent on any previous interaction between $S p$. pallida and the tissues, has been demonstrated in some animals. Thus Schlossberger (I927) ${ }^{1}$ showed that in mice inoculated with $S p$. pallida, or with $S p$. pertenuis, the virus spreads through the tissues without provoking any reaction. In both cases the animals were killed at varying intervals after inoculation, and portions of their lymph glands, spleen, blood and brain were inoculated into rabbits. Blood always failed to infect, but inoculations with lymph gland and spleen almost always succeeded, as did also brain in the case of two mice infected with $S p$. pallida and of two infected with $S p$. pertenuis. In another paper Kolle and Schlossberger (I928) ${ }^{2}$ reported that mice inoculated with $S p$. pallida as long as sixteen and a half months previously had been proved, by inoculation of their tissues into other animals, to be still harbouring the parasites though they had shown no sign of disease. In rabbits a certain small percentage after heavy intratesticular inoculation do not develop testicular lesions, but the glands of these " Nuller," as Kolle calls them, harbour $S p$. pallida, as proved by inocu- 


\section{EXPERIMENTAL RESEARCH IN SYPHILIS}

lations into other animals. Brown and Pearce (I924) ${ }^{3}$ quote Reasoner ${ }^{4}$ to the effect that infection of a rabbit may follow inoculation without the development of a primary lesion and relate experiments conducted by themselves in I92I which showed that after instillation of syphilitic virus into the intact preputial or conjunctival sac the animals became infected, but in some no primary lesion developed. The incubation was particularly prolonged (average fifty-four days in the case of the eye and fifty-nine in the prepuce), the primary lesions, when they occurred, were comparatively trivial in all but five rabbits out of the fifteen, and within the period of observation the metastatic lesions were mild. In contrast with this, control animals inoculated intradermally developed lesions of ordinary or even greater than ordinary severity, thus proving the virulence of the $S p$. pallida employed in the experiment. The authors suggest that, in similar circumstances of infection, the behaviour of the disease in man might be similarly mild, so that the disease would be overlooked. Kolle (I928) ${ }^{\mathbf{5}}$ points out that, if a female rabbit is inoculated on the vulva and after the resulting syphiloma has been allowed to heal is coupled with a male rabbit, this becomes infected, but the infection is usually symptomless, being proved only by inoculation of the male rabbit's lymph glands into other rabbits. Kolle suggests that the same thing may happen in man and that such symptomless, untreated human carriers may be an important cause of the spread of infection. $R$. Prigge $^{6}$ refers to the numerous cases of late syphilis in which there was no history of a chancre, and suggests that a proportion of men are like rabbits in this respect.

Thus natural " anergie" in respect of any reaction to $S p$. pallida has been proved to exist in mice and in respect of primary lesions at least in a percentage of rabbits. Does it occur in man? The suggestions of Brown and Pearce, of Kolle and of Prigge, that it may do so have been mentioned above. Possibly the same explanation may apply to some of the cases observed by Brandt (I922). ${ }^{7}$ These were prostitutes who escaped infection for a considerable number of years. Thus in I,I69 prostitutes were seventy-four who showed no sign of syphilis during periods of observation extending from two to over ten years. In the series were four of the lowest class who remained uninfected for eight to sixteen 


\section{BRITISH JOURNAL OF VENEREAL DISEASES}

years. The evidence of non-infection rested on persistent negative serum reactions and at least one negative cerebro-spinal fluid in each case. Also some of the women, after remaining free for years, did eventually become infected. I have experience of three cases in which no primary sore developed after inoculation into the skin, but in each of these an antiseptic had been applied shortly after the accident, so that they can hardly be described as cases of natural " anergie." Another example related by Audry (I926) ${ }^{8}$ is open to the same objection. In this case a woman who had contracted a dental infection, and had secondary symptoms with positive serum reactions, had meantime had marital relations with her husband, whose blood was then negative. Marital relations were stopped and the husband took stovarsol, but three months later his blood serum was positive though he had shown no clinical symptoms. As further evidence that his infection was recent, he responded easily to treatment. Possibly the explanation of the non-development of primary sores in these cases was that the tissues are slow to react at first, requiring a comparatively strong stimulus by the virus, and this was kept below the required strength by the action of the local antiseptic, or the stovarsol, according to the case. The same explanation may be applicable to the following in animals.

In rabbits Brown and Pearce (I920) ${ }^{9}$ have shown that the primary sore can be suppressed for some time, partially or wholly, by treatment with arseno-phenylglycyldichloro-m.-aminophenol, the effect of which in causing resolution of lesions is greater than its spirochæticidal action. They showed also that general symptoms were more certain to follow and more severe in degree in proportion to the extent to which the development of the primary sore had been inhibited ; this aspect of the subject is dealt with more fully below.

Temporary prevention of the development of a chancre without prevention of infection was demonstrated by Kolle (I924) $\mathbf{1 0}^{\mathbf{1 0}}$ and by Kolle and Evers (I926) ${ }^{\mathbf{1 1}}$ in rabbits injected with a bismuth compound. So long as the bismuth depot was present no chancre followed inoculation, though $S p$. pallida spread to the lymph glands. When the bismuth depot was cut out, even two to three months after the inoculation, a chancre 


\section{EXPERIMENTAL RESEARCH IN SYPHILIS}

developed. It is only fair to mention here that Levaditi and Fournier (I928) 12 strongly contested Kolle's view that bismuth only suppresses the development of the primary lesion without preventing the infection, reporting experiments which go to show that bismuth can not only prevent infection, but eradicate it when established ; this work will be reviewed later. Probably the reconciliation between Kolle and Evers' results and those of Levaditi and colleagues lies in the difference in the preparations of bismuth, that used by Kolle and Evers being absorbed only sufficiently to prevent chancre formation. All experimental work seems to show, in fact, that it is much easier to bring about " anergie" in respect of local response to inoculation than it is to prevent the spread of the virus into the tissues.

The foregoing has discussed the behaviour of the tissues in the face of first invasion by $S p$. pallida. It has shown little evidence of a natural ability of the tissues to resist invasion, but considerable evidence that in some animals the invasion may provoke no tissue reaction, this " anergie" being apparently absolute in all mice and in a certain percentage of rabbits, and being produced in rabbits and some human beings by treatment which is insufficient to destroy the infection.

The case is different when the first infection has lasted for some time. The evidence here is that after a time there is no response to a fresh inoculation, and the question whether this non-response is due to an acquired " anergie " or to the development of an active resistance to $S p$. pallida, or to both, is one on which all authorities are not yet agreed. Clinical evidence tells us that, if the tissues do develop actively antagonistic properties, these are insufficient of themselves to destroy the virus already there, whatever they may do to new $S p$. pallida introduced from without. Experimentally, also, Brown and Pearce (I92I) ${ }^{13}$ and numerous other workers have shown that, in syphilitic rabbits, after subsidence of active symptoms, the spirochætes remain in the lymphatic glands throughout the life of the animal. The proof of this is that, if one excises a lymph gland such as a popliteal and uses an emulsion, or a piece, of it for the inoculation of another rabbit (usually into the scrotum and testicle, but sometimes elsewhere), this rabbit becomes infected. Sometimes the first inoculation fails, but a 


\section{BRITISH JOURNAL OF VENEREAL DISEASES}

second succeeds ; sometimes it is necessary, for proof of continued infection of the first animal, to use for inoculation of the second a mixture of lymph glands, organs, such as spleen, liver and testicle, and other tissues, such as bone marrow. The failure of the tissues, whether human or rabbit, to rid themselves of the parasite is not, however, proof that no anti-spirochætal properties are developed, and the evidence on this point may now be reviewed.

In respect of antibodies to $S p$. pallida which can be demonstrated in vitro, the evidence is rather conflicting. Agglutinins have been demonstrated conclusively only against cultural spirochætes, and there is no evidence of opsonins. On the question of spirochæticidal properties of the serum, whether as a result of inoculations or of experimental infection of rabbits, except for experiments by Eberson, the evidence is that the serum of an animal either infected with living $S p$. pallida or inoculated with dead $S p$. pallida may be able to destroy or inhibit the growth of $S p$. pallida in cultures, but not those actively infecting an animal such as a rabbit. Eberson (I92I) ${ }^{14}$ has produced evidence of the development in the serum of infected rabbits and men, of spirochæticidal properties which are active against virulent $S p$. pallida. He used serum from patients suffering from syphilis in different stages and suspensions of three strains of $S p$. pallida, whose virulence for rabbits was proved. The serum had been heated at $54^{\circ} \mathrm{C}$. for twenty minutes and was from one to four weeks old. The technique was to mix 2 c.c. of the serum with $0 \cdot I$ c.c. of a suspension of $S p$. pallida containing fifteen to twenty organisms per field, incubate at $37^{\circ} \mathrm{C}$. for one and a half hours, and then inject into a rabbit's testicle. Sera from latent syphilitics with infections of three to twenty-five years' duration when tested in this way prevented infection of the inoculated rabbits. Some of the sera found to have protective properties were from treated cases of syphilis with negative Wassermann reactions. On the other hand, serum of patients with active lesions and of those with recent infections failed to protect. In rabbits with experimental syphilis of six to twelve months' duration, but with no active lesions, similar protective properties of the serum were found. Unfortunately, Eberson's work has not been confirmed by the other workers in this field, and all 


\section{EXPERIMENTAL RESEARCH IN SYPHILIS}

efforts at passive immunisation with the serum of animals either infected with syphilis or treated with dead virus have proved quite fruitless. Thus Dold and Worms (I928) 15 repeated and confirmed the experiments of Bruck (I928) ${ }^{16}$ with an anti-serum obtained from horses by F. Klopstock after inoculation with cultures of $S p$. pallida. This serum agglutinated Sp. pallida from cultures when in dilutions up to I in I0,000, but proved useless against actual syphilitic infections of animals. Dold and Worms also refer to failures by numerous workers with the llama's anti-serum, which was introduced by Jauregui and Lancelotti, and with Quéry's serum. Reiter (I928), ${ }^{17}$ after referring to a previous paper in which the serum of rabbits which had been infected experimentally or inoculated with pure cultures of $S p$. pallida had been shown to have no prophylactic value, tried the effect of active immunisation with living cultures administered intravenously a number of times, but these failed to protect against subsequent inoculation with testicle virus. Single intratesticular inoculations with living cultures of Sp. pallida failed similarly, and single intracisternal inoculations with living cultures at most only retarded the progress of a subsequent infection with testicle virus. Similarly inoculations with dead virus, or with $S p$. pallida which has been passaged through animals of other species in the hope of attenuating its virulence, have failed either to protect against subsequent infection or to modify the progress of existing disease.

The question of complement-fixation properties of the serum in combination with antigens of $S p$. pallida has been revived very actively in recent years. As you know, the idea that the Wassermann was a true BordetGengou phenomenon against $S p$. pallida received a severe blow when it was found by Landsteiner that, for the " antigen" in the test, alcoholic extracts of organs containing no Sp. pallida would serve, and as a matter of fact in most serum tests for syphilis, whether Wassermann or flocculation, the antigen most commonly employed is an alcoholic extract of healthy heart. Sachs, A. Klopstock, and Weil (I925, I926) 18, 19 injected rabbits with alcoholic extract of heart mixed with pig serum, and found that, after such inoculations, the serum of the rabbits behaved in Wassermann and flocculation tests exactly like syphilitic serum. The reac- 


\section{BRITISH JOURNAL OF VENEREAL DISEASES}

tion has been interpreted as due to antibody for lipoid, and the question as to whether this is lipoid of $S p$. pallida or of tissues is still under discussion. F. Klopstock (I926) 20 contends strongly that the reaction is anti-spirochætal-lipoid. He gives evidence to show that the first appearance of the serum reaction coincides with generalisation of the virus, not with the tissue changes which the virus evokes; he points out also that the reaction does not occur in other diseases causing degeneration of organs. He cites the work of others to show that organ extract will act as antigen without the activating help of foreign serum and reports the results of a number of experiments in which rabbits injected with alcoholic extracts of $S p$. pallida cultivated on artificial media became Wassermann and flocculation positive. Also that these extracts give reactions with syphilitic sera which compare favourably with those obtained with organ extracts. He acknowledges a close relationship between the lipoids resulting from action of $S p$. pallida on the tissues and lipoids of $S p$. pallida itself. Torii (I928), ${ }^{21}$ after a number of experiments with the serum of rabbits inoculated with lipoids of culture $S p$. pallida, of egg yolk and of rabbit organs, both healthy and syphilitic, concluded that Wassermann and flocculation reactions depend more probably on antibodies to organ-lipoids than on anti-spirochætal lipoid properties. His experiments showed that the Wassermann reaction evoked by inoculation with spirochætal lipoids and foreign serum is not so strong as that following injection of organ lipoids plus foreign serum, and that organ lipoids, but not spirochætal lipoids, will absorb the Wassermann reagine from a serum. Interestingly he showed also that, while an alcoholic extract of normal rabbit's testicle requires the addition of foreign serum to evoke in a rabbit Wassermann reagine, alcoholic extract of syphilitic rabbit's testicle will act alone. Torii thinks that in syphilis $S p$. pallida plays the same part in activating the antigenic properties of organ lipoids as does the foreign serum in the artificial production of Wassermann reagine.

Whatever further experiments may show to be the truth in this dispute, it is interesting that the Wassermann reaction, which has for long been characterised rather scornfully as an empirical test, has now been raised to the dignity of a true antibody phenomenon. 


\section{EXPERIMENTAL RESEARCH IN SYPHILIS}

Turning now from the humoral to the cellular side of the question, Bergel has for long maintained that the mononuclear cells, which are so prominent a feature in syphilitic infiltrations, are actively spirochæticidal by virtue of lipolytic enzymes which destroy $S p$. pallida. He states that in mixtures of lymphocytic extract and $S p$. pallida examined under dark-ground illumination the spirochætes can be seen to break up. In a fairly recent article (I928) ${ }^{22}$ he described in detail a series of histological examinations of rabbits' testicles following their invasion by $S p$. pallida which had been introduced into the peritoneal cavity. At first, when the spirochætes had just arrived at the testicles and were penetrating the vessels to the perivascular lymph-spaces, their appearance was normal, but in specimens taken at later dates when mononuclear leucocytic infiltration had occurred, he saw what he considered to be degeneration of the organisms until they had completely broken up into granules. $\mathrm{He}$ explains in this way the scarcity of spirochætes in tissues where there is much infiltration with mononuclear leucocytes. So far there has been no confirmation of these interpretations by other workers, and some strongly opposing views have been expressed. The well-known scarcity of visible $S p$. pallida in lymph-glands which inoculations prove to be infective will be discussed later.

On the whole, therefore, there seems to be little direct evidence of the development of properties antagonistic to virulent $S p$. pallida, whether as a result of infection or of vaccine treatment, though antibodies to $S p$. pallida from cultures have been demonstrated.

At the same time the indirect evidence afforded by reinoculation experiments, some of which are reviewed below, makes it difficult to avoid the conclusion that not merely " anergie" but effective antibody to $S p$. pallida results from interaction between this organism and the tissues. As mentioned earlier in this review, shortly after the development of a primary lesion a second primary lesion cannot be produced by reinoculation. That this is dependent on interaction of $S p$. pallida and the tissues and not merely on the presence of the original $S p$. pallida seems to be proved by a number of experiments. Omitting any detailed mention of early experiments by Bertarelli (I906 and I908), ${ }^{23}$ Truffi (I909), ${ }^{24}$ Purchkauer (I9II), ${ }^{25}$ and others, which go to show that keratitis produced by 


\section{BRITISH JOURNAL OF VENEREAL DISEASES}

inoculation of a rabbit's eye does not protect the other cornea from reacting to a reinoculation performed a little time after resolution of the lesions in the first eye, we pass on to the experiments of Uhlenhuth and Mulzer (I9I3), ${ }^{26}$ and others which showed that primary syphilitic keratitis in rabbits did not protect against chancre development following reinoculation of the scrotum, though a primary syphiloma of the testicle seemed to protect more strongly against keratitis following reinoculation of the eye. Manteufel and Richter (I926) ${ }^{27}$ showed that rabbits inoculated intravenously often develop an infection of the lymph glands but no outward signs, the infection being proved by successful inoculation of other animals with lymph glands of the intravenously inoculated animals. When the latent syphilitic animals were subsequently inoculated intradermally or intratesticularly a primary lesion followed in five out of six cases. Prigge and Rothermundt (I927) ${ }^{28}$ have also shown that rabbits which develop no chancre after inoculation but are infected can respond with a chancre to a reinoculation, though this is with homologus virus and more than ninety days (see below) after the first inoculation. On the other hand, as shown by other workers previously, with reservations to be mentioned presently, a primary syphiloma of the testicle and scrotal tissues protected against a second chancre following a reinoculation if this was performed sufficiently long after the first inoculation.

The matter was put on a more precise footing by the experiments of Kolle (I922), ${ }^{29}$ who showed that, if the first inoculation is into the testis, a second inoculation with the same strain of virus into the scrotal tissues carried out within sixty days may produce a chancre in 50 to 60 per cent. of cases. On the other hand, if the reinoculation is carried out between the sixtieth and ninetieth day, it is only occasionally successful, and if after the ninetieth day, practically never. Numerous workers have substantially confirmed these results, and the collection of records which has been made by Chesney ${ }^{30}$ shows 78.7 per cent. successful reinoculations from the twentieth to the sixtieth day, after the first; II.4 per cent. from the sixtieth to the ninetieth day; and 5 per cent. (three cases) after the ninetieth day. This is the case with homologus virus; the matter is different 


\section{EXPERIMENTAL RESEARCH IN SYPHILIS}

when another strain is employed for the reinoculation. It was shown by Fournier and Schwartz (I923) ${ }^{31}$ that infection with a strain from one case may not protect a rabbit from superinfection with a strain from another case. Chesney ${ }^{\mathbf{3 2}}$ has collected the results of reinoculations with heterologous virus which were carried out by Zinsser, Hopkins and McBurney, Reiter, Kolle and Chesney and Kemp, more than ninety days after the first inoculation. These resulted in over 44 per cent. of successes. As an example which illustrates the case more clearly may be quoted the experiments of Strempel and Armuzzi (I927), ${ }^{33}$ who reinoculated syphilitic rabbits with heterologous strains of $S p$. pallida more than four months after the first inoculation, with these results :-

\begin{tabular}{l|l|c|c}
\hline $\begin{array}{c}\text { Strain Used in First } \\
\text { Inoculatiou. }\end{array}$ & $\begin{array}{c}\text { Strain Used in Second } \\
\text { Inoculation. }\end{array}$ & No. of Rabbits. & $\begin{array}{c}\text { Percentage of } \\
\text { Successes. }\end{array}$ \\
\hline Nichols. & Truff. & 23 & $8 \cdot 7$ \\
Truffi. & Nichols. & 32 & $31 \cdot 3$ \\
Bonn. & Nichols. & 3 & $16 \cdot 7$ \\
Truffi. & Bonn. & 7 & $14 \cdot 3$ \\
Nichols. & Bonn. & I3 & $30 \cdot 7$ \\
\hline
\end{tabular}

Thus, although certain strains seem to be more strongly protective against successful reinoculation than are others, none seems to be absolutely dominant.

In man, so far as is known at present, acquired immunity against a second infection seems to apply to all strains, and there is some evidence to the effect that syphilis in man protects even against yaws. Thus Jahnel and Lange (I925) ${ }^{34}$ inoculated general paretics with $S p$. pertenuis from a rabbit's testicle and failed to get a primary lesion, though a normal person inoculated at the same time with the same strain was infected. Other experimental evidence on this point is rather conflicting. Some of the superinfections with yaws on syphilis and vice versâ which have been carried out on animals have been after too short an interval following the primary inoculation. Also, as mentioned, rabbits at least are susceptible to superinfection with heterologous strains of $S p$. pallida. From the epidemiological point of view the evidence of the absence or great rarity of syphilis in natives where yaws is endemic is at least suggestive. 


\section{BRITISH JOURNAL OF VENEREAL DISEASES}

The question of the persistence of resistance to reinoculation after eradication of the original infection has stimulated considerable experimental work. Kolle (I924) ${ }^{35}$ found that intensive and prolonged treatment of a rabbit when commenced more than ninety days after a successful syphilitic inoculation failed to make the animal respond with another chancre to a reinoculation. $\mathrm{He}$ argued from this, in accordance with Neisser's dictum, that the original infection had not been eradicated by the treatment. Chesney and Kemp (I924 and I925) ${ }^{\mathbf{3 6}}$ corroborated Kolle's findings as to failure to produce a second chancre in animals treated later than ninety days after the first inoculation, but expressed a disinclination to agree with Kolle's inference that the first infection had not been cured because inoculations of other rabbits with lymph gland material from their treated rabbits did not infect. Thus a series of syphilitic rabbits were treated each with six injections of " 606 " from forty-one to fifty days after their inoculation and another series were similarly treated I8I to 29I days after inoculation, while controls of both series were left untreated. At least fortynine days after completion of the treatment a single popliteal lymph gland from each rabbit was emulsified and inoculated into other rabbits. The glands from the treated animals failed to infect, and similar failure was experienced as late as 275 days after the treatment. The glands of the untreated controls infected other rabbits and were found to be still infective from 265 to 420 days after inoculation. The evidence that the treated animals had been sterilised appears thus to have been fairly strong, though there is the possibility, which is supported by the results of other workers, that although inoculation with the popliteal glands produced no chancre, other glands and organs, such as spleen, liver, etc., might have contained the virus. There is also the possibility that the popliteal glands taken from the treated animals may have contained virus in such small amount that it was insufficient to provoke primary syphilomata at the site of inoculation, though it produced a latent infection; on the tests applied to the rabbits inoculated with gland material from the treated animals the authors give no information.

The original animals were reinoculated with homologous virus at least forty-nine days after the treatment, 


\section{EXPERIMENTAL RESEARCH IN SYPHILIS}

and, while those which had been treated early became infected in 92 per cent. of cases, only one out of the thirteen which had been treated later developed any infection. Assuming, then, that the later treated animals had really been sterilised, the explanation of their failure to respond to reinoculation lay not in the fact of their still harbouring infection, as Neisser and also Kolle have believed, but in the development of a definite immunity. It should be added that the evidence of failure to reinfect in these cases rests, not only on the non-development of lesions, but on the noninfectivity of the rabbits' lymph glands and on the sera remaining Wassermann-negative. In a certain number of the rabbits treated early proof of successful reinoculation rested, not on the development of chancres, but on the glands becoming infective and the Wassermann reaction positive. The fallacy of relying on the non-appearance of clinical lesions for proof of non-infection after inoculation of rabbits has been pointed out by Brown and Pearce (I92I), ${ }^{37}$ Chesney (I923), ${ }^{38}$ Worms, ${ }^{39}$ Kolle and Schlossberger, ${ }^{40}$ and others.

Uhlenhuth and Grossmann (I928) ${ }^{41}$ referred to their previous work in which they had treated five rabbits in the latent stage four to eight months after inoculation, and two to five months after this had inoculated other animals from liver, spleen, bone-marrow and lymph glands of the treated animals, with negative results. Control inoculations of other animals with popliteal glands of latent syphilitic rabbits had been successful in ten out of twelve cases, so that failure to infect another animal by inoculation with popliteal lymph gland seems to be strong, though not absolute, evidence that the rabbit from which the gland came was non-syphilitic. The authors came to the conclusion as a result of their earlier experiments that, $(a)$ as pointed out by Brown and Pearce, after healing of syphilitic lesions rabbits still remain infected-that, in fact, spontaneous sterilisation does not occur; (b) rabbits with latent syphilis do not respond to reinoculation; and $(c)$ passage of glands and organs to other animals is a reliable method of testing for cure or otherwise. In their further series of experiments the authors treated sixteen syphilitic rabbits with massive doses of neosalvarsan from Ioo to 506 days after inoculation and, after the lapse of from three to ten months following treatment, tested their popliteal glands for 


\section{BRITISH JOURNAL OF VENEREAL DISEASES}

infectivity. All proved to be sterile. Fifteen were then reinoculated with the same (Truffi) strain of $S p$. pallida. None developed a chancre, but inoculations of other rabbits with cell organs and glands of eleven of the reinoculated rabbits showed that four of the eleven had become reinfected by the reinoculations. Thus seven of the rabbits were proved to have been sterilised by the treatment and to have become immune. This seems to be strong evidence against the theory of Neisser and of Kolle that failure to become reinfected proves persistence of the original infection ; it is strong evidence also against the dictum of Kolle that cure of syphilitic rabbits is impossible when treatment is commenced after the ninetieth day. In the case of the four whose organs and glands were infective for other rabbits after the reinoculations it might be argued that the infectivity dated back to the original infection, but the tests before reinoculation show this to have been very improbable. On the whole, the seven who were completely protected were in later stages when treated than were the four whose protection extended only to the non-development of a chancre on reinoculation. Thus Uhlenhuth and Grossmann's experiments support those of Chesney and Kemp. The authors suggest that complete immunity resulting from infection develops only very slowly and that it dies away slowly. They think, however, that great reserve should be exercised in applying the results of these experiments to man. [For example, by inferring from them that it would be a good thing in human syphilis to allow the disease to run on before commencing treatment.] Uhlenhuth and Grossmann found in the serum of their immune animals no evidence of antibodies and consider that resistance to reinfection is an attribute of the tissue cells.

Breinl and Wagner (I929) ${ }^{42}$ join with Chesney and Kemp, Voegtlin and Dyer, ${ }^{43}$ Uhlenhuth and Grossmann and Manteufel and Worms in opposing the views of Neisser, Kolle, Frei, Prigge and others that resistance to reinfection is dependent on persistence of the original infection. As they say, the overwhelming evidence is that the syphilitic rabbits treated by the former observers and found later to be resistant to reinfection had in fact been sterilised, and Prigge's experiments, in which the glands of rabbits treated with smaller doses 


\section{EXPERIMENTAL RESEARCH IN SYPHILIS}

of salvarsan remained non-infective only for a limited time are not an answer to those who oppose the Neisserian dictum. Breinl and Wagner point to the fact that the development of resistance to reinfection grows gradually with the age of the first infection. They quote Chesney's estima'e (already mentioned) derived from nine different investigations which show that " chancre immunity " is found :-

In $2 \mathrm{I} \cdot 3$ per cent. of rabbits after twenty to sixty days.

In 88.6 per cent. of rabbits after sixty-one to ninety days.

In $95^{\circ} \mathrm{O}$ per cent. of rabbits after ninety days.

Prigge's table of the development of chancre immunity in syphilitic rabbits which were eventually treated showed this to be present :-

In $25^{\cdot 2}$ per cent. of animals treated before the sixtieth day.

In $84^{\circ} 0$ per cent. of animals treated from the sixtieth to ninetieth day.

In IO0.0 per cent. of animals treated after the ninetieth day.

If the figures given by the two authors are separately plotted out, they give almost identical curves. These show a rise in the resistance, which is at first slow and then rapid, to a level which remains unchanged; in other words, the curves are typical of an immunisation curve. If Neisser's dictum that " chancre immunity " is bound up with survival of $S p$. pallida is correct, one would expect a sudden drop with sterilisation of the animal by treatment. To accept the idea that susceptibility to reinfection occurred contemporaneously with the death of the last spirochæte, one would have to assume that the tissues had not been changed by the presence of the spirochætes in them, since one could not believe that they would change from a non-susceptible to a susceptible state at a stroke. Breinl and Wagner thus believe that resistance to reinfection is an attribute of tissues which is developed slowly with the age of a syphilitic infection. and survives for a period at present unknown the sterilisation of the first infection. They draw attention to the fact, which will have become apparent to the reader, that there are two main degrees of resistance to reinfection-(I) mere " chancre immunity," or non-development of a new chancre, but nevertheless inability to prevent 


\section{BRITISH JOURNAL OF VENEREAL DISEASES}

reinfection, as proved by the glands and organs becoming infected; and (2) complete resistance, so that, after reinoculation, the animal's glands and organs remain sterile. They addressed themselves to the investigation of the fate of $S p$. pallida after reinoculation of this second group. They supposed three possible fates of these spirochætes.

(I) That they die off at the site of reinoculation.

(2) Or that they spread to the tissues, but succumb to the defensive forces of the body

(3) Or that they spread very slowly in the reinoculated animal and become demonstrable only after a very long time.

They employed four groups of rabbits, which were infected, sterilised with neosalvarsan at varying periods after infection and then reinoculated two or three months after the treatment. Subsequently the animals were bled to death and their organs, lymph glands, testicles and bone-marrow were inoculated into other rabbits to test for reinfection. In the first group of three rabbits treated on the eleventh to twenty-sixth days all were successfully reinoculated.

In the second group of nine rabbits sterilised on the forty-sixth to the fiftieth day, tests of the popliteal glands at varying periods after reinoculation showed a retardation of the spread of infection, since these glands were non-infective from the thirty-second to the fiftysixth day, but from the eightieth to the IoIst day five out of nine were found infective. It should be noted, however, that, as Worms and others have shown, noninfectivity of the popliteal glands does not prove noninfectivity of the whole animal ; in one of the rabbits in this group whose popliteal glands were non-infective on the I03rd day after reinoculation the spleen was infective. In the third group of five rabbits treated from the ninety-third to the I3oth day after first inoculation the result of reinoculation was that one (treated on the ninety-third day) developed a transient chancre, but the popliteal and other glands as well as organs proved I82 days later to be sterile. In another, treated on the I3oth day, the reinoculation graft was found to contain living $S p$. pallida on the thirteenth day after reinoculation, and its popliteal glands, but no other parts, were infective on the fifty-ninth day. In a third rabbit, without any 


\section{EXPERIMENTAL RESEARCH IN SYPHILIS}

chancre having developed after reinoculation, the glands, organs, etc., were found to be infective I3I days later. In the remaining two rabbits of the group, which were despatched and their glands, organs, etc., inoculated into other animals on the twenty-ninth and I2oth days respectively after reinoculation, no trace of infection could be found.

In the fourth group of five rabbits treated on the 274th to 4I2th day after first inoculation, tests made on the 59th to I92nd day after reinoculation showed this to have been successful only once. In no case did any chancre develop after reinoculation.

Since generalisation of the virus after reinoculation sometimes occurred in animals treated from the 274th to 4I2th day after first infection, and, on the other hand, some animals resisted reinoculation when the first infection had been treated between the ninety-third to the I3oth day, the animal's constitution, as well as the duration of the infection, is a factor of considerable importance. Broadly, so far as the small number of tests will permit of an inference, chancre immunity is the first to develop and genuine immunity much later, though in some animals it was found to have developed when the first infection had lasted only forty-six to fifty days. Between these two extremes are cases $(a)$ where $S p$. pallida penetrates only to the popliteal gland, and $(b)$ where the virus remains localised at the site of reinoculation without giving rise to any tissue reaction.

In connection with the non-development of a chancre in syphilitic rabbits sterilised long after the disease commenced and then reinoculated, your experience of reinfection in human beings probably coincides with mine, that in most of such cases the treatment of the first infection was commenced in the very early days of the disease. Halley and Wassermann (I928) ${ }^{44}$ presented a study of 676 cases of reinfection reported in the literature, and, after rejecting 447 as inadmissible, have added to the remaining 229 cases, eight from the Johns Hopkins Hospital. Analysis of the histories of these 237 cases showed that 97.8 per cent. had been treated in the primary and secondary stages. In 83 of the 232 treated early the duration of the infection at the time of first treatment was known, and in practically all it was less than sixteen weeks, while in 82 per cent. it was less 


\section{BRITISH JOURNAL OF VENEREAL DISEASES}

than eight weeks. The fact that, on reinoculation of rabbits after sterilisation of the original infection, no chancre appears though the animal is infected (as proved by transfer of its lymph glands to other animals) suggests that possibly human beings may become reinfected without the development of a second primary sore. Such an event might reasonably be suspected as Chesney and Kemp (I926) ${ }^{45}$ have suggested, in some of the human cases in which, after remaining serologically negative for many months, the reactions have become positive. $R$. Prigge ${ }^{46}$ thinks also that in syphilitic persons who have responded well to very thorough treatment, but have later shown symptoms, the explanation may have been a chancreless reinfection. In the same connection may be repeated the suggestion by Kolle (I928), ${ }^{\mathbf{4 7}}$ mentioned above, that syphilis may be spread to a certain extent by carriers who have shown no symptoms, and have consequently never been treated.

The influence of injury in determining the site of a recurrence of syphilis must have struck many syphilologists; I have personally demonstrated very many examples of it. Experimental evidence of the effect of injury in breaking down resistance has been afforded by Chesney and Kemp (I926). These workers treated a series of sixteen rabbits whose infections had been allowed to run on for more than five months, and, after proof of sterilisation, reinoculated them on granulating wounds which had been produced on the animals' backs. In contrast with the experience when in such circumstances the reinoculation was into a testicle and very rarely reinfected the animals, the reinoculations into the damaged areas provoked chancres in 50 per cent. of cases. In a more recent article, Chesney, Turner and Halley (I928) $\mathbf{4 8}$ relate the results of a number of experiments which demonstrate the same fact. In a number of rabbits wounds of the back were produced by excision in each case of an area about $3 \times 4 \mathrm{~cm}$., and these were then allowed to heal. Before or after complete healing the animals were inoculated, either intratesticularly or intravenously. In two cases rabbits inoculated intratesticularly developed syphilomata in the inoculated testicles about the twenty-first day, and syphilitic lesions were present in the scars on the back as early as the fortyeighth day, no lesions being present elsewhere. In 


\section{EXPERIMENTAL RESEARCH IN SYPHILIS}

three others similarly inoculated testicular lesions appeared on the twentieth day, and syphilomata in the scars on the animals' backs on the thirty-seventh to the forty-fourth day. In each of four rabbits two wounds were made on the back, one twenty-two days later than the other, and eight days after the date of the second wounds the animals were inoculated intravenously. At this time the first wounds had healed in three of the rabbits. In the eight healed or granulating wounds syphilitic lesions appeared in nineteen days in one, in twenty days in one, twenty-seven days in three, in thirtythree days in two and in sixty-seven days in one. In control animals inoculated subcutaneously with the same virus, primary lesions appeared in from nineteen to twentyseven days, so that in the wounded animals the scars must have become infected very shortly, if not immediately, after the inoculation. The results of the intravenous inoculations in these cases are striking considering that intravenous inoculation usually results in latent infection (see Manteufel and Richter above). The syphilomata took very closely the shapes of the scars, e.g., stellate in some cases. The authors relate two clinical cases illustrating the same point ; in one syphilitic lesions were particularly well marked in recent scars of burns; in the other they were concentrated in keloid scars resulting from razor wounds on the face, trunk and arms. The authors refer to papers by Klauder (I922), ${ }^{49}$ by Dohi (I909), ${ }^{50}$ and by Keidel and Zimmermann (I9I8) ${ }^{51}$ on the same subject.

The foregoing has demonstrated the great influence of the interaction between $S p$. pallida and the skin on the development of resistance to the parasite. In the same connection a number of experiments by Brown and Pearce (I920) ${ }^{\mathbf{5 2}}$ are very suggestive. They showed that interference with the development of the primary lesion favoured the outbreak of generalised lesions. In twenty rabbits which were inoculated in both testicles fourteen were castrated at an early stage of the development of primary lesions ; generalised lesions occurred in thirteen of the fourteen castrated rabbits and in only one of the six controls. In twenty-seven rabbits which were inoculated in only one testicle, fourteen were castrated and thirteen of these developed general lesions. In the thirteen controls of this series, in contrast to the controls in the series inoculated in both testicles, eight developed 


\section{BRITISH JOURNAL OF VENEREAL DISEASES}

general lesions. In a third group the development of the chancre was interfered with by the administration of a therapeutic agent. The group consisted of twentyfour rabbits, twelve were inoculated in both testicles, and six were treated. Five of the treated and one only of the untreated developed generalised lesions. Twelve were inoculated in only one testicle, and six were treated. All of the treated and three of the untreated showed well-marked generalised lesions. In a further series ten rabbits were inoculated on one side of the scrotum, and testicle and scrotum were amputated forty-eight hours later. Eight of the ten had developed generalised lesions as early as seven weeks later, and two others did so a little later. The experiments show clearly that, in rabbits, the extent and severity of the primary lesion have a profound effect on the development of generalised lesions. On the other hand, the experiments of Brown and Pearce (I924) ${ }^{53}$ which have been mentioned above, show that, in certain circumstances, both primary and general lesions may be very mild. It is possible that in these cases (infection through intact mucous membrane) the dose of virus reaching the submucous tissues was so low that the tissues were, temporarily at least, able to hold it in check. Following on the demonstration of the effect of a primary syphiloma in preventing or modifying the development of generalised lesions, Brown and Pearce (I92I) ${ }^{54}$ have shown that in rabbits generalisation tends to follow a certain order. Thus they say " bone lesions, if they occur at all, tend to follow those of the testicles or scrotum, while keratitis and iritis occur towards the end of the cycle of tissue involvement, the skin and mucous membranes occupying an intermediate position. Further than this, it has been shown that, by early and radical interference, it is possible to so alter the course of the disease as to cause bone lesions practically to supplant those of the testicle in the defensive reaction; conversely, by permitting the testicular reaction to progress to a given point, it is possible to confer protection on this group of structures. In this case no bone lesions occur, but the generalised disease begins with involvement of the next group of tissues in order, producing an infection which is essentially one of the skin, mucous membranes and eyes."

Similarly, as they point out, although inoculation into 


\section{EXPERIMENTAL RESEARCH IN SYPHILIS}

both testicles seems to confer a protection which extends in most cases to other tissues, it may not reach the eyes. They think that these facts, if applicable to man, have a special significance to the development of neuro-syphilis. One would refer in this connection to the great incidence of neuro-syphilis in human cases treated in the early stages with arsenobenzene alone. One can imagine that the arsenobenzene stopped the interaction between most of the tissues and the virus, and so deprived the next order of tissues in the sequence, those of the central nervous system, of adequate protection.

The evidence presented above on the defence elaborated by the tissues against $S p$. pallida leaves me in sympathy with the views of Brown and Pearce (I92I), ${ }^{55}$ which they have expressed in the following terms :-

"From a consideration of the phenomena which characterise both human and animal infection, there are three conditions which possess a peculiar significance on account of the insight which they give into the nature and mechanism of defensive reactions ; these are latency, relapse and progression or the sequence observed in the evolution of the disease.

"The phenomenon of latency in syphilis is one of the most striking examples in all medicine of the distinction between infection and disease; but the significance of this phenomenon has not been fully appreciated. A rabbit once infected with Spirochata pallida harbours virulent organisms for the remainder of its life, and yet active manifestations of disease may be difficult to detect at any time and are rarely observed after the first few months of the infection.

"The fact that infection may exist over long periods of time with no appreciable manifestations of disease indicates that there are two elements in the defensive reaction of the infected animal which bear no fixed relation to each other. One of these is directed against the spirochæte itself, but is apparently of less consequence from the standpoint of the evolution of disease than the other, whose object is the neutralisation of toxic or harmful effects.

"These two reactions proceed in parallel directions, but are not developed to an equal extent. In the animal the prime object of the defensive reaction is the prevention or repair of harmful effects ; and, as a rule, this is 


\section{BRITISH JOURNAL OF VENEREAL DISEASES}

accomplished within a comparatively short period of time. In like manner, growth and multiplication of spirochætes are inhibited to an unknown extent so that the infection itself is brought under control. It is significant, however, that while the defensive reaction is carried to the point of complete neutralisation of the power of the organism for the production of the disease, infection is never abolished.

"The distinction drawn between these two elements of the defensive reaction is of fundamental importance, and the failure to draw a clear line of demarcation between the two processes has caused some confusionnotably, in our conception of syphilitic immunity.

"A second feature of syphilitic reactions which is deserving of especial consideration is the relapsing course of the disease. In the experimental animal periodicity is observed in the development and resolution of individual lesions of all classes as well as in the evolution of the disease as a whole ; relapse of healed lesions and relapse associated with the development of new lesions are also observed, but not as often as in man.

"If one may regard a lesion as primarily an expression of toxic injury on the one hand and of a defensive or protective reaction on the other, an analysis of the phenomena of periodic development and resolution of individual lesions leads to the conclusion that there is a quantitative relationship between the injury produced by the spirochæte and the reaction of the host ; that when the injury has been checked the reaction tends to decline, but as not all spirochætes are destroyed in this process, the cycle is repeated, the state of resistance mounting with successive repetitions until the surviving organisms are incapable of producing further injury.

"This process is multiplied many times over in the progress of the disease, with long or short intervals of quiescence or freedom from active lesions. Relapse is prone to occur, however, and it can be shown experimentally that the resistance acquired is definitely related to the extent or severity of the injury which the organism causing the infection is capable of producing. Moreover, the margin of resistance above that required for protection against this organism may be very slight and wholly insufficient to protect against one of greater virulence. In fact, for reasons which are not as yet 


\section{EXPERIMENTAL RESEARCH IN SYPHILIS}

clear, an animal infected with an organism of low virulence may be less capable of defending himself against one of high virulence than a normal animal.

" A study of the phenomena of relapse, therefore, brings out the fact that the defensive or protective reactions of the animals are directly related to injurythat the resistance acquired may be transient or relatively enduring, but tends to increase as the infection progresses, until it is sufficient to afford a safe margin of protection against the organism causing the infection."

Reference has been made in this review to the fact that often $S p$. pallida cannot be demonstrated microscopically in infected glands. This has led Levaditi, Schoen and Sanchis-Bayarri (I927) ${ }^{56}$ to revive the idea that $S p$. pallida has a life-cycle. They quote Truffi, ${ }^{57}$ who contrasted the virulence of lymph glands of syphilitic rabbits with the absence microscopically of spirochætes. Truffi's experience coincided with those of Uhlenhuth and Mulzer and, at a later date, Brown and Pearce (I92I), 58 who, in microscopical examinations of twenty-nine virulent glands, found $S p$. pallida only three times. Levaditi and colleagues in examinations of thirty-three glands of syphilitic rabbits found no typical spirochætes, but doubtful forms in two or perhaps three specimens. In a search for stages in the development of $S p$. pallida they examined grafts of infective glands at varying intervals after these had been implanted in the scrota of other rabbits, and saw in them various forms with a great affinity for the silver stain. These forms, which they considered to be possibly stages in the life-cycle of $S p$. pallida, had the following shapes :-

(I) Moniliform-filaments with wide undulations and with swellings, sometimes at the ends, sometimes in body.

(2) Club-or dumb-bell shaped, with one or two terminal swellings.

(3) Loops which were not quite closed and were like figures of 8 or of $\mathrm{U}$.

(4) Closed rings.

(5) Compact balls.

(6) Like comma stops, or interrogation marks.

(7) Granules from $0 \cdot 3 \mu$ to $0 \cdot 4 \mu$ in dimensions.

(8) Granules which were almost ultramicroscopic.

Some references have been made above to experi- 


\section{BRITISH JOURNAL OF VENEREAL DISEASES}

mental work bearing on treatment. Space will not permit of this being dealt with here in any detail, but a few investigations may be mentioned.

The effect of raising a rabbit's temperature on the development of syphilitic lesions after inoculation has been investigated by Schamberg and Rule (I926 and I928). ${ }^{59}$ The method of raising the temperature which was chiefly employed was to put the animals into hot baths at $\operatorname{II} 3^{\circ} \mathrm{F}$. for fifteen to twenty minutes daily. They found that a series of such baths commenced within three or four days after inoculation, and raising the body temperature by an average of $4^{\circ} \mathrm{F}$., could prevent infection. In another series rabbits with primary chancres were similarly treated, and in two weeks the chancres had completely healed. An untreated control still had a hard chancre containing numerous $S p$. pallida seventy-five days after inoculation. The rise of temperature provoked in the two treated rabbits amounted to $5.2^{\circ} \mathrm{F}$. in one and $5.8^{\circ} \mathrm{F}$. in the other. The authors quote experiments by Weichbrodt and Jahnel (I9I9) ${ }^{60}$ in which rabbits with chancres were placed in an incubator at $4 \mathrm{I}^{\circ} \mathrm{C}$. for about half an hour twice a day, and in from three to five weeks the chancres had healed. Bessemans, De Potter and Hacquaert (I928) ${ }^{61}$ have arrived at the conclusion that raising a syphilitic rabbit's temperature by hot baths so that the lesion is kept at $40^{\circ} \mathrm{C}$. or more for one or more hours causes rapid healing.

Schamberg and Tseng (I927) ${ }^{62}$ treated some patients on the same lines. They found it possible to raise the patients' temperatures to $106^{\circ} \mathrm{F}$. with safety and noted a certain degree of improvement in cutaneous manifestations.

Brown and Pearce (I927) ${ }^{63}$ exposed rabbits inoculated with syphilis, respectively to (I) diffuse sunlight filtered through window-glass, (2) constant and continuous artificial light with a wave-length of from 3,022 to 5,790 Angström units, and (3) darkness. The results showed a smaller frequency of metastatic orchitis and of generalised lesions in the groups left in constant light than in the other two, and generally that "the efficiency of the reaction to infection increased with the amount of light received and with the constancy of the exposure."

The influence of the endocrine system on resistance of rabbits to syphilitic infection has been studied by Brown, Pearce and C. M. Van Allan (I923) ${ }^{64}$ The possibility I96 


\section{EXPERIMENTAL RESEARCH IN SYPHILIS}

that the animal's resistance is subject to the same influences as are concerned in the regulation of growth and the maintenance of general metabolic activities as well as to the endocrines was first suggested to the authors by the occurrence of marked seasonal changes in the severity of the disease, and especially by the abnormal resistance displayed at times by pregnant and lactating female rabbits. By a comparison of the condition, weights, etc., of the organs of I39 rabbits infected with syphilis with those of a large series of normal rabbits and of animals suffering from various non-syphilitic affections, the authors established the fact that in the syphilitic rabbits the organs showed distinct changes which were especially noticeable in the thyroid, parathyroid and thymus. Also, after the establishment of control and immunity, such organs as the thyroid, parathyroids, suprarenals maintained a change suggestive of a higher plane of functional activity. Altogether the severity of the disease seemed to be inversely proportional to the activity of the glands mentioned. These observations suggested experiments to determine whether the course of a syphilitic infection could be altered by interference with any of the endocrine glands or by the administration of such agents as mercury and iodide, neither of which "possesses any considerable spirochæticidal action in doses below the lethal limits, but have been found to produce marked changes in the endocrine glands and the lymphoid tissues." The results showed that "by either of the methods mentioned the general character of and course of the disease may be greatly modified ; that the resistance of infected animals may be augmented or depressed by one and the same agency; that the immediate effect is proportional to the stimulation or depression of the activity of this system of organs." In these experiments the lymphoid tissues acted in harmony with the endocrine. After mentioning the enormous field for investigation which is opened up by these experiments, suggesting as they do the tremendous dependence of the infected animal on the health of those organs which govern metabolic activity, the authors conclude as follows: "Again, it appears that the maintenance of immunity is in some way dependent upon the functioning of this mechanism at a new and probably a higher level which is necessitated by the presence of an 


\section{BRITISH JOURNAL OF VENEREAL DISEASES}

infection which must be kept under continuous control. The state of heightened activity or constant stress may in turn account for the eventual physical deterioration and predisposition to other forms of disease which so often occur in syphilitic individuals. Finally, these experiments also serve to indicate what may be accomplished by a system of therapy that is intended to reinforce the resistance of the patient. At the same time they serve as a warning of the dangers that may be encountered by attempting to treat syphilis without due regard for the effects of such treatment upon the patient or from illadvised efforts to alter the action of the mechanism concerned in maintaining constitutional resistance."

With such views all who have reflected on the varying response of syphilitic patients to treatment will doubtless express full agreement. The tendency to-day in treatment of patients who respond indifferently to treatment is too greatly to push on blindly, in the hope that mere weight of remedy will eventually annihilate the parasite, and too little to examine the patient's constitution to try to discover in this the cause of his poor response.

The effect of bismuth and of tellurium in preventing infection of rabbits after inoculation has been investigated in considerable detail by Levaditi, Sanchis-Bayarri, Schoen and Manin (I927 and I928) 65, 66, 67. It would be quite impossible to do justice to their work in the space available here, and only general conclusions can be given. With regard to both metals, it was found that protection against inoculation persisted so long as a certain minimal amount was incorporated in the tissues apart from those at the site of inoculation. The bismuth experiments were conducted with basic tartrate of bismuth (Trépol) and with bismuth in fine subdivision (Néo-trépol). A sufficient dose of Trépol protected against inoculation up to ${ }^{52}$ days after injection, while Néo-trépol protected only two out of nine rabbits for as long as seventy-three days. Chemical analysis of the organs showed a lower metallic content (metallic potential) in the case of bismuth metal, while at the sites of injection there was evidence of less absorption. The authors think that bismuth is absorbed after conversion to a proteo-metallic compound and that this conversion is more easily performed in the case of a compound than in that of the metal itself. 


\section{EXPERIMENTAL RESEARCH IN SYPHILIS}

In another series, Levaditi, Sanchis-Bayarri and Manin showed that the injection of the maximum tolerated dose of a soluble preparation of the double iodide of bismuth and quinine (" solubyl ") protected rabbits against inoculation performed five days later, but if the inoculation was delayed for thirty-one days infection followed. Thus the protection following injection of a soluble salt, which is more quickly absorbed and secreted, is not so lasting as that following injection of an insoluble.

The dependence of a therapeutic effect of bismuth on a certain minimal amount of the metal being incorporated in the tissues has been demonstrated by the authors in other experiments, and assuming that their findings are applicable to the treatment of syphilis in man, they show that the choice of compound in the bismuth therapy of syphilis is a matter of considerable importance.

In conclusion, I would again remind you that this review does not pretend to be more than a slight summary of the experimental work which has been carried out. I would beg you not to formulate opinions on the soundness of any of the work and views which I have mentioned until you have consulted the original articles, because a reviewer, with every desire to be fair, may be unconsciously biassed and present the evidence which supports his own ideas more prominently than that which favours the opposite opinion.

\section{REFERENCES}

(I) Schlossberger, H. Centr. f. Bakt., I. Abt., Orig., I927, civ., 237 ; Med. Klin., I929, xxv., 307.

(2) Kolle, W., and Schlossberger, H. Deutsche med. Wchnschr., I928, liv., I29.

(3) Brown, W. H., and Pearce, L. J. Exp. Med., I924, xxxix., 645.

(4) Reasoner, M. A. Am. J. Syph., I9I7, i., 478.

(5) Kolle, W. Centr. f. Bakt., I. Abt., Orig., I928, cvi., I34.

(6) PrIGGe, R. Deutsche med. Wchnschr., I927, liii., I340.

(7) BRANDT, R. Wien. klin. Wchnschr., I922, Nr. Io, 223.

(8) Audry, C. Bull. Soc. Franç. Dermat. et Syph., I926, xxxiii., 216.

(9) Brown, W. H., and Pearce, L. Arch. Derm. and Syph., r920, ii., 675 .

(10) Kolle, W. Deutsche med. Wchnschr., I924, 1., I074.

(II) Kolle, W., and Evers, E. Deutsche med. Wchnschr., I926, lii., 557.

(I2) LEVADiti, C., and Fournier, L. Lancet, I928, i., 692.

(I3) Brown, W. H., and Pearce, L. J. Exper. M., xxxiv., I85.

(I4) Eberson, F. Arch. Derm. and Syph., I92I, iv., 490.

(I5) Dold, H., and Worms, W. Klin. Wchnschr., I928, vii., 2140. 


\section{BRITISH JOURNAL OF VENEREAL DISEASES}

(I6) BRUCK, C. Klin. Wchnschr., I928, vii., ref. Dold and Worms.

(I7) REITER, H. Klin. Wchnschr., I928, vii., I539.

(i8) Sachs, H., Klopstock, A., and WeIl, A. J. Deutsch. med. Wchnschr., I925, li., 589.

(I9) SACHS, H., and KlOPSTOCK, A. Deutsche med. Wchnschr., I926, lii., 650 ; ibid., I927, liii., 394.

(20) Klopstock, F. Deutsche med. Wchnschr., I926, lii., 226 ; Klin. Wchnschr., I928, vii., I896.

(2I) ToRII, F. Japan J. Derm. and Syph., I928, xxviii., 43.

(22) BERGEL, S. Klin. Wchnschr., I928, vii., I68I.

(23) Bertarelli, E. Centr. f. Bakt., I. Abt., Orig., I908, xlvi, 5r.

(24) Truffi, M. Centr. f. Bakt., I. Abt., Orig., I909, lii., 555.

(25) Purchkauer, R. Arb. a. d. kais. Gsndhtsamte, I9II, xxxvii., 569.

(26) Uhlenhuth, P., and Mulzer, P. Arb. a. d. kais. Gsndhtsamte, I9I3, xliv., 307 .

(27) Manteufel, P., and Richter, A. Deutsche med. Wchnschr., I926, lii., 2II3.

(28) Prigge and Rothermundt. Derm. Ztschr., I927, 1., I69.

(29) Kolle, W. Deutsche med. Wchnschr., I922, xlviii., I30I.

(30) Chesney, A. "Medicine Monographs-Immunity in Syphilis," I927, xii., 20. London: Baillière, Tindall \& Cox.

(3I) Fournier and Schwartz. Ref. Levaditi et al., Ann. Inst. Past., I928, xlii., I05.

(32) Chesney, A. Loc. cit., p. 2 I.

(33) Strempel, R., and ArmuzzI, G. Deutsche med. Wchnschr., I927, liii., II34.

(34) JAHnel, F., and LANGe, J. Münch. med. Wchnschr., I925, lxxii., I452.

(35) Kolle, W. Deutsche med. Wchnschr., I924, 1., I235.

(36) Chesney, A., and KemP, J. E. J. Exp. M., I924, xxxix., 553 ; ibid., I925, xlii., I7.

(37) Brown, W. H., and Pearce, L. Proc. Exp. Biol. and Med., I92I, Xviii., 255.

(38) Chesney, A. J. Exp. M., I923, xxxviii., 627.

(39) Worms, W. Deutsche med. Wchnschr., r926, lii., 785.

(40) Kolle, W., and Schlossberger, H. Deutsche med. Wchnschr., I926, lii., I245.

(4I) Uhlenhuth, P., and Grossmann, H. Ztschr. f. Immunol. $u$. Exp. Therap., I928, lv., 380 .

(42) Breinl, F., and WAgneR, R. Ztschr. f. Immunol. u. Exp. Therap., I929, lx., 23.

(43) Voegthin, C., and Dyer, H. A. Public Health Reports, I925, xl., $25 \mathrm{II}$; ibid., xlii., I76.

(44) Halley, C. R. L., and Wassermane, H. Arch. Intern. M., I928, xli., 843 .

(45) Chesney, A., and Kemp, J. E. J. Exp. M., I926, xliv., 589.

(46) PrIGge, R. Deutsche med. Wchnschr., I927, liii., I340.

(47) Kolle, W. Centr. f. Bakt., I: Abt., Orig., I928, cvi., I34.

(48) Chesney, A. M., Turner, T. B., and Halley, C. R. L. Bull. Johns Hopkins Hosp., I928, xlii., 3I9.

(49) Klauder, J. V. J. Am. M. Assn., I922, lxxviii., I029.

(50) DoHI, S. H. Arch. Derm. u. Syph., I909, xcvi, 3.

(5I) Keidel, A., and Zimmermann, E. L. Am. J. Syph., I9I8, ii., 3. 


\section{EXPERIMENTAL RESEARCH IN SYPHILIS}

(52) Brown, W. H., and Pearce, L. Arch. Derm. and Syph., I920, ii., 675 .

(53) Brown, W. H., and Pearce, L. J. Exp. M., I924, xxxix., 645.

(54) Brown, W. H., and Pearce, L. Arch. Derm. and Syph., I92I, iii., 254.

(55) Brown, W. H., and Pearce, L. J. Am. M. Assn., I921, lxxvii., I6I9.

(56) Levaditi, C., Schoen, R., and Sanchis-Bayarri, V. Bull. Acad. Med., I927, xcviii., I49; Annal de l'Inst. Past., I928, xlii., 475.

(57) Truffi, M. Pathologica, I9I3, ref. Levaditi.

(58) Brown, W. H., and Pearce, L. J. Exp. M., I922, xxxv., 39.

(59) Schamberg, J. F., and Rule, A. M. Arch. Derm. and Syph., I926, xiv., 243 ; ibid., I928, xvii., 322.

(6o) Weichbrodt, R., and JAhnel, F. Deutsche med. Wchnschr., I9I9, xlv., 483.

(6i) Bessemans, A., De Potter, F., and Hacouaert, R. C. R. Soc. Biol., I928, xcix., I6ro ; ibid., I6I6.

(62) Schamberg, J. F., and Tseng, Hsien-wu. Am. J. Syph., I927, xi., 337.

(63) Brown, W. H., and Pearce, L. J. Exp. M., I927, xlv., 497.

(64) Brown, W. H., and Pearce, L. Proc. Soc. Biol. and Med., r923, $\mathrm{xx} ., 476$.

(65) Levaditi, C., and Manin, Y. C. R. Soc. Biol., I927, xcvii., 655.

(66) Levaditi, C., Sanchis-Bayarri, V., Schoen, R., and Manin, Y. Annal de l'Inst., I928, xlii., I05.

(67) Levaditi, C., Sanchis-Bayarri, V., and Manin, Y., C. R. Soc. Biol., I927, xcvii., I687. 